$\begin{array}{ccc}\text { UNIVERSITA } & \text { DEPARTMENT OF } \\ \text { DEGLISTUDI } \\ \text { DI TORINO }\end{array}$

\title{
SHOULD WE RESURRECT 'TIPP FLOTTANTE' IF OIL PRICE BOOMS AGAIN? SPECIFIC TAXES AS FUEL CONSUMER PRICE STABILIZERS
}

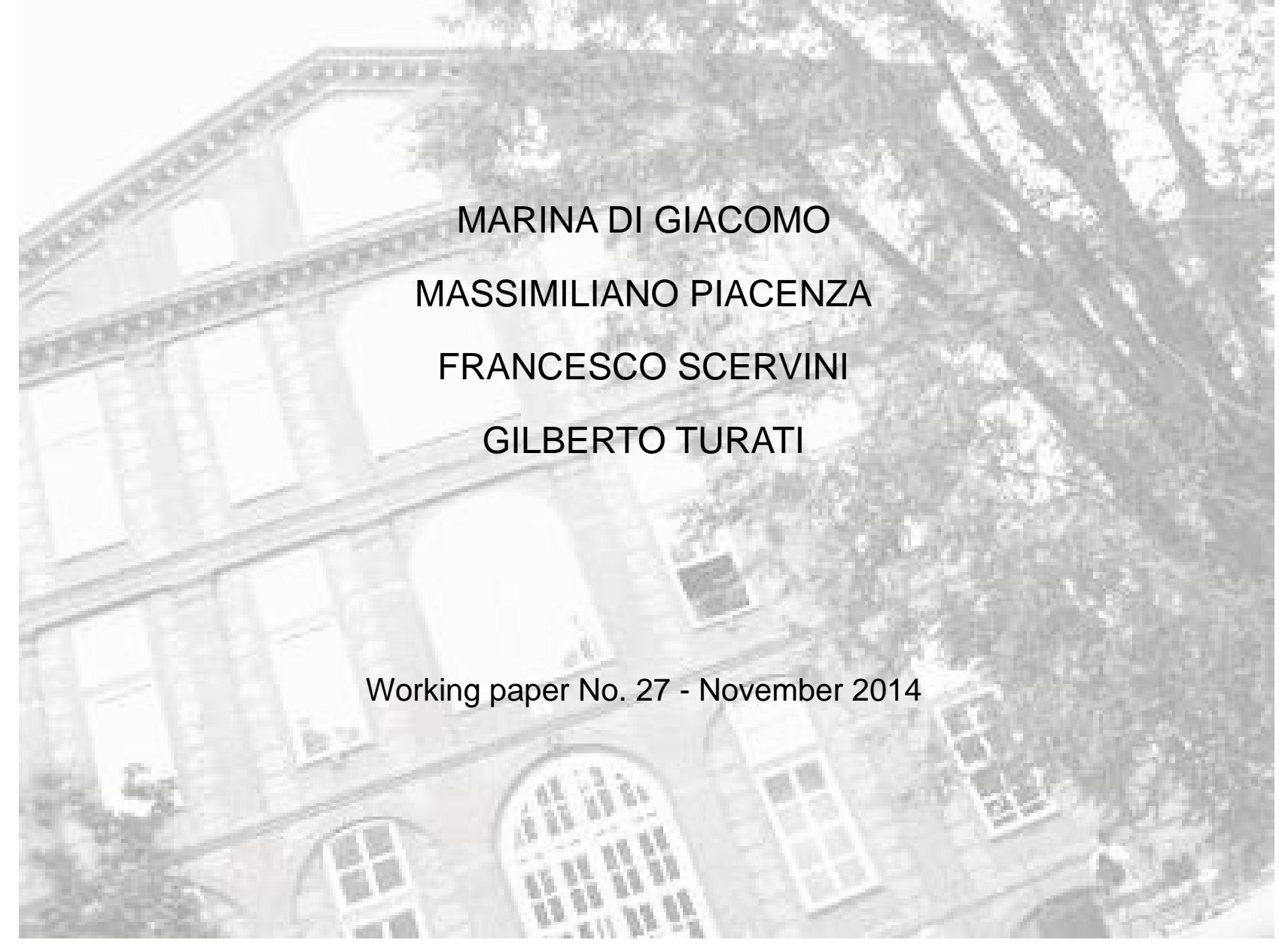




\title{
Should we resurrect 'TIPP flottante' if oil price booms again? Specific taxes as fuel consumer price stabilizers*
}

\author{
Marina Di Giacomo ${ }^{\dagger} \quad$ Massimiliano Piacenza ${ }^{\ddagger}$ \\ Francesco Scervini $^{\S} \quad$ Gilberto Turati $₫$
}

November 27, 2014

\begin{abstract}
As an answer to soaring oil prices, stabilization mechanisms based on specific taxes, such as the French 'TipP flottante', have been discussed and introduced in some countries in early 2000s, but then soon abandoned. Our contribution aims at analysing the excise passthrough and the cost shifting in a comprehensive European context to understand whether such a mechanism could actually reach its target. Our results show that, on average, fuel tax reductions are effective in stabilize consumer price, but the measure is particularly costly for public budgets.
\end{abstract}

JEL codes: H22 (Taxation, Subsidies, and Revenue - Incidence), Q41 (Energy - Demand and Supply, Prices), Q48 (Energy - Government Policy), D24 (Production and Organization - Costs)

Keywords: Fuel markets, Tax incidence, Excise pass-through, Price stabilization, Oil price.

${ }^{*}$ The authors thank Massimo Filippini for the insightful suggestions and the participants to the 70th annual congress of the International Institute of Public Finance and to the XXVI annual meeting of the Italian Association of Public Economics.

${ }^{\dagger}$ University of Turin, Esomas - marina.digiacomo@unito.it

$\ddagger$ University of Turin, Esomas - massimiliano.piacenza@unito.it

$\S$ University of Turin, Esomas - francesco.scervini@unito.it - Corresponding author

ฯ University of Turin, Esomas - gilberto.turati@unito.it 


\section{Introduction}

The oil price boom experienced since the beginning of the new millennium, which has brought prices to soar from an average of about $20 \$$ per barrell during the Eighties and the Nineties to a peak of more than $140 \$$ in 2008 , caused several protests by consumers, that resolutely asked in latest years for an effective government intervention to cap price increases. One of these policies - which has been discussed in many countries, especially in Europe, but really implemented only in very few of them - originates from the simple observation that final fuel prices for consumers include a large (and complex) share made up by a blend of different taxes. ${ }^{1}$ The intuition is then to implement a mechanism which 'automatically' modifies the tax component of the final price to consumers for any movement of the oil price on international markets. ${ }^{2}$ For instance, this is the idea behind the French TIPP flottante, introduced by the left-wing Jospin's Government from the October 2000 to the July 2002: in response to a $10 \%$ increase (decrease) of the Brent crude oil price, the $T_{I P P^{3}}$ (the excise on the consumption of energy products, now $T I P C E$ ) has been modified by the same amount in the opposite direction so as to compensate the increase in value added tax (VAT), which - in Europe is applied both to the price and to the specific tax. Similar mechanisms have been introduced in Portugal and even in some US states at about the same period, but then abandoned when crude oil price went down consistently below the January 2000 level in the second half of the year 2002. Interestingly, despite the sharp increase registered in oil prices from then up to summer 2014 (when oil price dropped by around 25\% from a long-period average well above $100 \$$ ), the mechanism has not been reintroduced (or introduced) in any countries. For instance, in Italy the Parliament passed a law defining a fuel price stabilizer in 2008, but the left-wing government has never applied it due to budgetary reasons; moreover, the conservative UK government received a negative advice from the Office of Budget Responsibility [OBR, 2010] to the

\footnotetext{
${ }^{1}$ In virtually all western European countries the total tax burden on fuel is between $50 \%$ and $70 \%$ of the final consumer price, about two third of which is due to specific taxes and one third to value added taxes.

${ }^{2}$ The mechanism was clearly described by the UK Prime Minister David Cameron in January 2011: 'Is there a way in which when the oil price goes up and the Treasury is getting more revenue out of oil we can find a way of sharing the risk with the consumer? If the price goes up, the tax comes down, and if the price comes down the tax goes up. We're looking at that [...] I would love to find some way of sharing the risk of higher fuel prices with the consumer, because at the moment I think they feel they are sharing all of the burden.' [The Guardian, 2011].

${ }^{3}$ Taxe intérieure sur les produits pétroliers.
} 
introduction of a fuel price stabiliser in $2011 .{ }^{4}$

The evaluation of the 2000-2002 French experience made by the national Court of Auditors points to two main issues: first, since transport fuel taxes represent about 1.2\% of GDP in France [Eurostat, 2013], the measure can be extremely costly for the public budget; second, it is not socially efficient, since reducing taxes on fuel could make consumers less aware of the impact of their choices on the environment. Also the independent commission appointed by the French government shared the same negative view on the TIPP flottante. However, despite the relevance of these two arguments, both the evaluations by the Court of Auditors and by the commission unfortunately miss a key element to inform the public discussion, which revives as soon as fuel prices increase: ${ }^{5}$ Does the TIPP flottante effectively work as fuel price stabilizer?

Also the economic literature has not discussed deeply into the matter. A first branch of literature investigates the tax incidence on fuel price in different frameworks. For instance, Chouinard and Perloff [2004] analyze first the incidence of federal and state specific gasoline taxes in the US, and then also the incidence of state ad valorem taxes [Chouinard and Perloff, 2007]; Alm et al. [2009] study the incidence of state excises in the US retail gasoline market, while Doyle and Samphantharak [2008] analyze the incidence of gasoline state sales taxes using very detailed data on daily prices at the station level. All these papers find a complete, or almost complete, pass-through of taxes on to consumer prices. More recently, a second branch of literature focuses more deeply on the factors that may affect the excise pass-through: Marion and Muehlegger [2011] investigate the elasticity of supply, finding a negative relation between constraints in the supply chain and the pass-through rate; Jametti et al. [2013] take into account the market concentration, finding an under-shifting of fuel taxes on consumer prices when market are more concentrated; finally, Kopczuk et al. [2013] argue that the pass-through rate depends on tax remittance responsibility, due to different opportunities of tax evasion.

However, to the best of our knowledge, only the paper by Di Giacomo et al. [2012] addresses directly the issue of automatic mechanisms based on taxes to compensate oil price variations, considering the case of Italy, another European country where several governments have discussed of implementing a sort of this mechanism, but never did so. Their simulations suggest that the mechanism is ineffective in stabilizing wholesale prices, but they also point

\footnotetext{
${ }^{4}$ In 2012 the government introduced a 'Fair Fuel Stabiliser', but the mechanism is different: it creates a cap to the increase of duties, that cannot increase more than the inflation rate if the crude oil price exceeds $45 £$ per barrel.

${ }^{5}$ The reintroduction of TIPP flottante was widely discussed during the French presidential electoral campaign in 2012.
} 
out an important role by VAT, which - interacting with the specific tax increases the ability of governments to efficiently block prices. There are two main limitations in this analysis: considering a single country in a period in which VAT did not change, Di Giacomo et al. [2012] were unable to identify the real pass-through of VAT and, more importantly, they were forced to consider net wholesale prices, instead of final gross prices to consumers.

In this paper we extend their analysis in two directions considering a panel of European countries. Exploiting time and cross-sectional variability in VAT, we identify the pass-through of VAT besides the one related to the excise, analyzing how a mechanism like the TIPP flottante can impact on the final consumer price. Our main result suggests that the automatic mechanism is able to stabilize consumer prices, but the whole burden is sustained by the public budget. One should then weight the expected benefits from stabilizing fuel prices with the costs in terms of lower revenues for state finances in order to assess whether the stabilization policy should be implemented or not.

The remainder of the paper is structured as follows. Section 2 provides an essential theoretical framework for understanding the economics of a measure like the TIPP flottante. Section 3 translates this framework in an empirical strategy for the identification of key effects. Section 4 is devoted to the data, while Section 5 presents and discusses our results, including a simulation of a 'TIPP flottante'-like mechanism. Brief concluding remarks follow.

\section{Theoretical framework: can the TIPP flot- tante work?}

In this section we develop a simple theoretical model to understand under which conditions price stabilization policies can effectively neutralize crude oil price volatility on final consumer price, building on the work by Delipalla and Keen [1992] on specific taxes in oligopolistic markets. Let us start from the definition of the fuel post-tax consumer price $C P$, the target of stabilization policies:

$$
C P^{f}=\left(P^{f}\left(\text { oilP }, e x c^{f}, v a t^{f}, X^{f}, \varepsilon^{f}\right)+e x c^{f}\right) \cdot\left(1+v a t^{f}\right)
$$

where $P$ is the (stochastic) pre-tax consumer price; exc and $v a t$ the excise and the value added tax, respectively; oil $P$ the crude oil price; $X$ is a vector of demand and supply shifters; $\varepsilon$ is an idiosyncratic shock; and the superscript $f$ identifies the type of fuel, either gasoline, $g$, or diesel, $d$. Eq.(1) makes clear that the VAT interacts both with the pre-tax price and the specific tax.

Consider an oligopolistic market where $m>1$ identical petrol stations compete à la Cournot. The product is homogeneous and - for large volumes 
- it is produced at constant marginal (and average) costs $c\left(\right.$ oilP, $\left.e x c^{f}\right)$, with $\partial c / \partial o i l P>0 .{ }^{6}$ Each station $j$ maximizes the following profit function:

$$
\Pi_{j}^{f}=\left(P^{f}-c\left(\text { oil } P, e x c^{f}\right)\right) q_{j}^{f}
$$

by choosing the optimal quantity $q_{j}$. Solving eq.(1) for $P^{f}$ and substituting in the profit function (2) we obtain:

$$
\Pi_{j}^{f}=\left(\frac{C P^{f}\left(Q^{f}\right)}{1+v a t^{f}}-e x c^{f}-c\left(o i l P, e x c^{f}\right)\right) q_{j}^{f}
$$

where $C P^{f}\left(Q^{f}\right)$ is the market demand function and $Q^{f}=\sum q_{j}^{f}$ is the aggregate quantity of fuel supplied by the $m$ petrol stations active in the market. The first order condition for profit maximization is:

$$
C P^{f}\left(Q^{f}\right)+q_{j}^{f}\left(\frac{\partial C P^{f}\left(Q^{f}\right)}{\partial Q^{f}} \frac{\partial Q^{f}}{\partial q_{j}^{f}}\right)=\left(e x c^{f}+c\left(o i l P, e x c^{f}\right)\right)\left(1+v a t^{f}\right)
$$

where $\partial Q^{f} / \partial q_{j}^{f}$ represents each station's conjecture about the effect of its own output change on total industry output $Q^{f}$ (which is equal to 1 in a Cournot setting; see for instance Colangelo and Galmarini [2001]). Summing eq.(4) over all stations we obtain:

$$
C P^{f}\left(Q^{f}\right)\left(1-\frac{1}{m \varepsilon\left(C P^{f}\left(Q^{f}\right)\right)}\right)=\left(e x c^{f}+c\left(o i l P, e x c^{f}\right)\right)\left(1+v a t^{f}\right)
$$

where $\varepsilon\left(C P^{f}\left(Q^{f}\right)\right)=-\frac{C P^{f}\left(Q^{f}\right)}{Q^{f}} \frac{\partial Q^{f}}{\partial C P^{f}\left(Q^{f}\right)}$ is the price elasticity of demand. To ensure stability (and the second order condition for profit maximization), we define $g\left(C P^{f}\right)=1-\frac{1}{m \varepsilon\left(C P^{f}\right)}$ and, following the literature, we assume that $g\left(C P^{f}\right)>0 .^{7}$

Eq.(5) implicitly defines the equilibrium post-tax consumer price. To understand whether the TIPP flottante can work, we need to differentiate eq. (5) with respect to both the oil price and the excise, that is, under the second order condition:

$$
\Delta C P^{f}=\frac{1+v a t^{f}}{g\left(C P^{f}\right)}\left(\frac{\partial c}{\partial o i l P}\right) \Delta o i l P+\frac{1+v a t^{f}}{g\left(C P^{f}\right)}\left(1+\frac{\partial c}{\partial e x c^{f}}\right) \Delta e x c^{f}
$$

\footnotetext{
${ }^{6}$ Notice that excise may affect the cost function on top of the direct 'accounting' effect on consumer price made clear in eq.(1). We will focus on this effect below.

${ }^{7}$ The same results could be achieved under the less restrictive assumption that $g\left(C P^{f}\right)=\left(1-\frac{1}{m \varepsilon\left(C P^{f}\right)}\right)\left(1-\eta\left(C P^{f}\right)\right)>0$, where $\eta\left(C P^{f}\right)=\frac{C P^{f}}{\varepsilon\left(C P^{f}\right)} \frac{\partial \varepsilon\left(C P^{f}\right)}{\partial C P^{f}}$ is the price elasticity of the elasticity of demand. For the sake of simplicity, in the text we assume that $\eta\left(C P^{f}\right)=0$, that is: elasticity of demand does not change when prices change.
} 
according to which, if $\Delta e x c^{f}=-\Delta o i l P$, consumer prices are stabilized if:

$$
\frac{\partial c}{\partial o i l P}=\frac{\partial c}{\partial e x c^{f}}+1
$$

In order to understand the stability condition in eq.(7), let us first analyse a simple case in which there are no imperfections, as in Weyl and Fabinger [2013], and crude oil is the only input in the fuel production function. These simple assumptions would imply that $\frac{\partial c}{\partial o i l P}=1$ and $\frac{\partial c}{\partial e x c^{f}}=0$ : an increase of crude oil price rises marginal costs one to one and excise does not alter the production function, resulting only in a one to one accounting increase of total costs (the second term in the right hand side of eq.7). Therefore, a crude oil price increase rises proportionally the marginal costs and the excise reduction perfectly balances this increase. The profit-maximizing quantity in eq.(4) is unaffected, as it is the producer price and the final consumer price. Indeed, the stabilization condition in eq.(7) is always satisfied.

However, under a more realistic perspective, there is no reason to assume that $\frac{\partial c}{\partial o i l P}=1$, since the fuel production function involves several processes and inputs and is also intimately related to the production of other oil products. Moreover, the different degree of vertical integration and the market structure might affect the reaction of producers to changes in the prices of inputs [Borenstein and Shepard, 2002, Hastings and Gilbert, 2005]. Finally, also the excise might have additional effects on top of the accounting effect: on the one side, there might be non-linear administrative costs associated to the introduction of an excise; on the other side, there may be different opportunities for tax evasion/avoidance, as described in a recent paper by Kopczuk et al. [2013]. Finally, again, market structure and vertical integration may affect the way each producer react to the change of excise. For all these reasons, $\frac{\partial c}{\partial e x c^{f}}$ may be different from zero. In this case, the condition in eq.(7) is not trivial and makes it explicit that stabilization mechanism can be effective only if the effect of crude oil price on marginal costs is perfectly balanced by the direct and indirect effects of the excise.

Since we cannot observe the marginal costs of fuel producers/retailers, we cannot directly estimate eq.(7). However, if we assume that producers and retailers set an (unobservable) constant mark-up on costs, we can replace the marginal cost with the producer price and focus on the following condition:

$$
\frac{\partial P^{f}}{\partial o i l P}=\frac{\partial P^{f}}{\partial e x c^{f}}+1
$$

We devote the remaining sections of the paper to estimate eq.(8), to test whether the pass-through of excise and the cost shifting balance out in the price stabilization mechanism. 


\section{$3 \quad$ Empirical strategy}

As discussed in the previous section, the economic rationale behind price stabilization is that - if the pass-throughs on consumers of both marginal costs and taxes are similar - a counteracting variation of the excise when the crude oil price increases can stabilize prices. To estimate these effects we recall eq.(8) and consider the following linear model:

$$
\begin{aligned}
P_{i, t}^{f} & =\beta_{0}+\beta_{1} \text { oil }_{t}+\beta_{2} e x c_{i, t}^{f}+\beta_{3} v a t^{f}+ \\
& +\beta_{4}\left(\text { oil } \times v a t^{f}\right)_{i, t}+\beta_{5}\left(\operatorname{exc}^{f} \times v a t^{f}\right)_{i, t}+ \\
& +X_{i, t}^{\prime} \beta_{6}+M_{t}^{\prime} \beta_{7}+\eta_{i}+\theta_{t}+\varepsilon_{i, t}
\end{aligned}
$$

where the main variables are defined as before; $i$ and $t$ identify country and time period, respectively; the matrix $X$ includes a set of country-specific time trends of first, second and third order; finally, the model includes monthly dummies, $M$, to account for seasonal variation in the demand for fuel, country fixed effects $(\eta)$, year fixed effects $(\theta)$, and the usual idiosyncratic error term $(\varepsilon)$. Moreover, to account for possible serial correlation within groups, we also cluster the standard errors at year, month and country levels (see Cameron et al. [2011] for multiway clustering). ${ }^{8}$

After estimating the linear regression model in eq.(9), we are able to compute the variation of pre-tax consumer price due to a variation of the crude oil price and a variation of the excise as:

$$
\frac{\partial P^{f}}{\partial o i l P}=\hat{\beta}_{1}+\hat{\beta}_{4} \overline{v a t}^{f}
$$

and

$$
\frac{\partial P^{f}}{\partial e x c^{f}}=\hat{\beta}_{2}+\hat{\beta}_{5} \overline{v a t}^{f}
$$

respectively, where $\overline{v a t}$ is the sample average of VAT. Following from eq.(8), the condition for the stabilization mechanism to be effective requires:

$$
\frac{\partial P^{f}}{\partial o i l P}-\frac{\partial P^{f}}{\partial e x c^{f}}-1=\left(\hat{\beta}_{1}-\hat{\beta}_{2}\right)+\left(\hat{\beta}_{4}-\hat{\beta}_{5}\right) \overline{v a t}^{f}-1=0
$$

\footnotetext{
${ }^{8}$ In our case, as required by the methodology developed by Cameron et al. [2011], year and month clusters are non-nested, since month dimension refers to the common shocks that might happen at the same month of all years in all countries, such as a demand increase due to summer holidays. This kind of shocks is non-nested in year dimension. However, we replicate the empirical analysis clustering only at year and country level and results are essentially unchanged.
} 
Consistently with the theory, this condition suggests that what matters for stabilization are the pass-throughs of both the crude oil price and the excise, which are influenced also by the role played by the VAT.

Together with the baseline model in eq.(9), we also consider several alternative specifications as robustness checks. ${ }^{9}$ First, given the large number of variables involved in the country-specific time trends, which might affect the statistical significance of the main coefficients, we also estimate the basic model by dropping all the country specific time-trends $\left(X_{i, t}^{\prime}\right)$. Second, one may question whether the effects of crude oil price and excise on pre-tax price really depend on the level of the VAT. To control for this, we also exclude the two interacted terms (imposing $\beta_{4}=\beta_{5}=0$, as in all the existing literature not considering the effects of VAT). Third, our estimates may be affected by the fact that our main specification does not include any demand or supply shifter. For this reason, we replace the set of country-specific time trends with some market shifters, such as the relative number of retailers, the relative number of vehicles, the share of elderly people and per-capita GDP. Unfortunately, these controls are not available for all countries in all periods, and all of them are available only quarterly or yearly. ${ }^{10}$ Fourth, as suggested by Di Giacomo et al. [2012] and even more clearly by Jametti et al. [2013], the pass-through of excises can be affected by the market concentration. However, systematic information on the degree of competitiveness for each country are not available, and we were able to collect only the market share of the largest retailer from several national sources. ${ }^{11}$ Hence, to catch these effects, we follow two different routes re-estimating the baseline model: by including interaction terms of our main variables with country specific time trends, ${ }^{12}$ and by including interactions with the market share of the largest retailer. Fifth, there are no theoretical reasons to assume that the

\footnotetext{
${ }^{9}$ We also try to estimate the two equations for gasoline and diesel using a seemingly unrelated regressions (SUR) model [Zellner, 1962] to account for the possible correlation between the two models. However, even if the correlation between residuals is significant $(\hat{\rho}=.40)$, SUR estimation is not suitable to take into account the panel structure of the data and to cluster standard errors. In any case, since results are very similar in the two models, we present in the paper only the fixed effects model. Results from SUR estimates are available from the authors upon request.

${ }^{10}$ The data availability of controls is the main reason why we choose the regression with country-specific time trends instead of market shifters as our baseline specification. However, as shown below, results on price stabilization are virtually the same in both models.

${ }^{11}$ Since we analyse the final consumer price, we think the retailers' market share is the best measure to capture the market concentration.

${ }^{12}$ These country specific trends pick up also the differences in tax evasion allowed by the market segment that is called to remit taxes by the law [Kopczuk et al., 2013].
} 
effects of crude oil price and excise on fuel price are constant rather than isoelastic. To control also for this second assumption, we re-estimate the baseline model taking the logarithms of all variables.

Finally, endogeneity issues may also arise: even if not officially stated by the laws, ${ }^{13}$ the policies on excises might depend on the level of consumer prices. A first, narrative reason to reject endogeneity is that - considering our sample - governments have decided to change the nominal value of excises only 156 times for gasoline and 179 times for diesel, that is, on average, about one adjustment per year in each country. Given the high volatility of crude oil price and of the other determinants of fuel price, one may assume that variations of excise are not driven by changes of the fuel price. However, in order to statistically rule out any endogeneity issues, we also estimate two further models: first, we exclude from the sample the two countries (France and Portugal) that explicitly implemented, even if for a short period of time, a price stabilization policy; second, we instrument excises on fuel with excises on tobacco, that are clearly independent of any fuel price stabilization policy. ${ }^{14}$

\section{Data}

Our main data source is the European Commission Oil Bulletin, ${ }^{15}$ that includes several information on a wide range of energy products on a weekly basis for all EU countries. We focus only on gasoline and diesel, and - for each of these two products - we collect data on pre-tax price (defined as 'consumer prices excluding duties and taxes'), excise and value added tax. A second relevant source of data is Datastream, ${ }^{16}$ from which we collect the weekly crude oil price. Notice that, since we focus on the European markets, we consider the Brent crude oil price, instead of the WTI (West Texas Intermediate) oil price, the benchmark for the US market. All prices and excises have been discounted using the Eurostat consumer price index on 'food and non-alcoholic beverages'. ${ }^{17}$ Other control variables include demand-side vari-

\footnotetext{
${ }^{13}$ In our sample of countries, price stabilization mechanisms were implemented only in France and Portugal for a very short period, as discussed in the introduction.

${ }^{14}$ The information are available on the European Commission Communication and Information Resource Centre for Administrations, Businesses and Citizens (CIRCABC, https://circabc.europa.eu). Standard tests confirm that this is a valid instrument.

${ }^{15}$ http://ec.europa.eu/energy/observatory/oil/bulletin_en.htm as of March 17, 2014.

${ }^{16}$ http://thomsonreuters.com/datastream-professional/ as of March 17, 2014.

${ }^{17}$ We decide to use the food CPI instead of the more intuitive 'all-goods' CPI in order to avoid a possible source of endogeneity, since the latter is clearly more influenced than
} 
ables, such as per capita GDP, the number of vehicles, the population and the share of people over 65 , derived from Eurostat, ${ }^{18}$ and a supply-side variable, the number of retailers, derived from the Unione Petrolifera ${ }^{19}$ statistical service.

In order to minimize potential distortions in our analysis, we make a strict selection of countries and periods to include. As for countries, since crude oil is traded in US Dollars and the exchange rate volatility may affect the retail price, we focus only on countries in the Eurosystem after the definition of fixed exchange rates against the Euro. ${ }^{20}$ Moreover, because of the short period of observation, we exclude all the countries that introduced the Euro after 2007: Slovenia (2007), Cyprus and Malta (2008), Slovakia (2009), Estonia (2011), Latvia (2014). As for the time dimension, while price and tax variables are available at weekly frequency, control variables are registered either quarterly (GDP), or yearly. We decide therefore to collapse weekly data at monthly level, taking the maximum values of prices (pre-tax fuel prices and crude oil price) and taxes (both excise and VAT) registered in each month and each country. We are then left with a panel consisting of 12 countries $^{21}$ observed for 168 months (between 1999 and 2012), for a total of 1,998 observations. $^{22}$

Table 1 shows the descriptive statistics for all the variables in the empirical analysis. Pre-tax price of diesel is higher than pre-tax price of gasoline, while the opposite is true for the excise. In absolute terms, excises are higher than pre-tax price for gasoline, and lower for diesel. VAT on gasoline and diesel is different only in Luxembourg until 2004. Because of EU legislation, excises on tobacco are measured as a share of final price; however, the size is similar to excises on fuel. Finally, the sample size of control variables is lower than the full sample, in particular because of the high number of missing observations on the number of retailers and of vehicles per capita.

\footnotetext{
the former by fuel prices.

${ }^{18}$ http://epp.eurostat.ec.europa.eu/portal/page/portal/eurostat/home/ as of March 17, 2014.

${ }^{19}$ The Italian oil producer association, http://www.unionepetrolifera.it/it, that collects consistent data on several European countries.

${ }^{20}$ December $31^{\text {st }}, 1998$ for all countries apart from Greece, whose fixed rate was established on June $20^{\text {th }}, 2000$.

${ }^{21}$ Austria, Belgium, Finland, France, Germany, Greece, Ireland, Italy, Luxembourg, the Netherlands, Portugal, Spain.

${ }^{22}$ The panel is not perfectly balanced because Greece is observed only 150 times, since the Dracma/Euro exchange rate was fixed on June 2000.
} 


\section{Results}

\subsection{Evaluating pass-throughs}

Tables 2 to 4 show estimation results for all the models described in section $3 .^{23}$ The stability of the coefficients estimates changes according to the variable considered: while the coefficients for crude oil price are fairly stable across specifications, those of the tax variables and their interactions are more volatile. However, the presence of interacted terms makes single coefficients difficult to read about the actual effect of changes in crude oil price and taxes on the pre-tax and post-tax consumer price. We then compute the marginal effects (the two sides in eq.(8)) for each specifications, using the delta method to evaluate their statistical significance. These effects are reported in tables 6 to 8 . Differently from single coefficients, the total effects are very stable across specifications and fuel types: first, the derivative of pre-tax price with respect to crude oil price (eq.10) is slightly lower, but not statistically different from 1 in all specifications for both gasoline and diesel, apart from columns (3), (4) and (6) of table $7 .^{24}$ This means that producers/retailers are able to almost fully shift production costs on to final consumers. Second, also the excise pass-through is not statistically different from 1 in most of the models. Interestingly, as for the crude oil price, it is always lower than 1. Hence, analogously to production costs, producers/retailers are able to almost fully shift also the fiscal burden on the consumers, leaving almost unaffected the pre-tax fuel price (i.e., the net price they receive). Even when they are not able to fully shift the excise, its weight falls on consumers for about $80 \%$ and on producers/retailers for the remaining $20 \%$, that is the estimated effects on pre-tax price. These findings are fully in line with previous literature on tax incidence in the fuel markets. ${ }^{25}$

\footnotetext{
${ }^{23}$ Table 5 includes first-stage regression results, showing that instruments are relevant and exogenous.

${ }^{24}$ In the constant elasticity model (columns 3 and 6 of table 3 ), the regression coefficients have a different meaning and eq.(10) and eq.(11) should be restated as $\frac{\partial P^{f}}{\partial o i l P}=$ $\left(\hat{\beta}_{1}+\hat{\beta}_{4} \overline{v a t} f\right) \cdot \frac{\bar{P}^{f}}{\overline{o i l P}}$ and $\frac{\partial P^{f}}{\partial e x c^{f}}=\left(\hat{\beta}_{2}+\hat{\beta}_{5} \overline{v a t}^{f}\right) \cdot \bar{P}^{f} \overline{e x c}^{f}$, respectively, where upper bars refer to the sample averages. These are functions of $P^{f}$, oilP, exc ${ }^{f}$, and VAT.

${ }^{25}$ Results are also in line with the findings in Di Giacomo et al. [2012] for Italy. They focus only on pre-tax prices, finding that there is a positive pass-through of producers' costs and no pass-through of excise on pre-tax prices. Following our notation in eq.(1), they find that $\partial P^{f} / \partial o i l P>0$ and $\partial P^{f} / \partial e x c^{f} \approx 0$, consistently with our results. In particular, the variation of pre-tax price due to a .10 euro decrease of excise is .0035 euro (table 5, pag.1184), while we find .0022 in the baseline model (table 6). Stated differently, $\partial P^{f} / \partial e x c^{f}=-.022$ in our paper and $\partial P^{f} / \partial e x c^{f}=-.035$ in Di Giacomo et al. [2012]. Relying on these findings, they conclude that price stabilization mechanisms are ineffective
} 
Overall, our estimates show that the sign and the magnitude of excise pass-through and cost shifting are slightly lower than 1 and very similar to each other. Indeed, the difference between them, as in eq.(12), is never statistically different from zero in all the models and for both gasoline and diesel (third and last rows of tables 6 to 8), apart from the model with constant elasticities for diesel. Therefore, we can conclude with reasonable confidence that, on average, the two effects balance each other.

\subsection{Simulating the automatic stabilization mechanism}

The first three rows of tables 6 to 8 show our main result on the effect of the stabilization mechanism on post-tax consumer price, net of VAT, represented in eq.(12), the empirical counterpart of eq.(8). As previously discussed, stabilization mechanisms are effective if the difference between the two pass-throughs is not different from zero. The results are very clear: in almost all models the effect is never significantly different from zero. Hence, according to simulations, the stabilization mechanism seems actually able to effectively counteract oil price increases.

Tables 6 to 8 include the simulated final consumer price and its variation assuming an increase of crude oil price by 10 cents and a decrease of the excise by the same amount. Starting from the initial price, ${ }^{26}$ we compute the final price and the difference, taking the VAT rate at the average EU level. In the light of the previous results, the changes in post-tax consumer price are low and unsurprisingly never statistically significant (from eq.(6) and eq.(8) we see that the condition for $\Delta C P^{f}=0$ is the same as for $\frac{\partial P^{f}}{\partial o i l P}-\frac{\partial P^{f}}{\partial e x c^{f}}-1=0$, that is why we report in the tables only the test for the latter condition). Therefore, the price stabilization policy discussed in this paper seems to be effective in neutralize the volatility of crude oil price on consumer prices.

\subsection{Discussion}

The empirical results discussed in previous sections provide supportive evidence on the effectiveness of mechanisms such as the TIPP flottante in counteracting the impact of crude oil price volatility and in stabilizing final consumer prices. This evidence relies on the virtually full pass-through of both the production costs and the fiscal burden from the producers/retailers

in stabilizing wholesale prices, while we take a step forward, predicting also an almost full stabilization of consumer prices.

${ }^{26}$ Notice that this price is not estimated, but simply computed from the data applying eq.(1) with the observed $P^{f}$. This explains why standard errors are not reported. 
to the consumers. For this reason, it may seem surprising that price stabilization mechanisms received so little attention and were implemented only in very few cases.

As noticed in the introduction, there are two main issues related to fuel price stabilization: the impact on public budgets and environmental concerns. With respect to the latter, if fuel taxes were purely Pigouvian taxes aimed only at correcting the social costs related to the fuel consumption, then i) they should be unaffected by crude oil price volatility, as far as the negative externality of fuel consumption is unrelated to oil price; ii) they should not have any impact on public budget, since tax revenues should be used to compensate social costs from the negative externalities. However, either statements do not find application in the real world: first, the amount of fuel taxes is proportional to the crude oil price, due to the VAT component; second, fiscal agencies are very careful in estimating the effects of excise variations on the public budget, and in several cases they rejected or dissuaded governments to implement such policies. ${ }^{27}$ As a further narrative prove that fuel taxes are not mainly Pigouvian, Eurostat [2013] classifies transport fuel taxes as 'energy taxes' and transport non-fuel taxes as 'environmental taxes'. This does not mean that there are no positive effects of fuel taxes on the production of negative externalities, but only that environmental purposes do not seem the main driving reason why governments levy taxes on fuel.

The special attention of fiscal authorities on fuel taxes leads us to the former issue related to price stabilization policies, that is public budget sustainability. First, it must be pointed out that - because of the full pass-through of taxes on consumers - the costs of fuel price stabilization lie entirely on public budgets, since the producers/retailers are virtually unaffected by excise volatility. ${ }^{28}$ Second, fuel taxes play a relevant role in public budgets: according to Eurostat [2013] estimates, on average they account for $1.6 \%$ of GDP both in Euro- 27 and in Euro area, and for $4.7 \%$ and $4.3 \%$ of total taxation in Euro-27 and Euro area, respectively. ${ }^{29}$ Therefore, an automatic fuel

\footnotetext{
${ }^{27}$ For instance, the French Court of Auditors was worried about the budgetary effects of the TIPP flottante, the UK Office of Budget Responsibility rejected a former version of the Fair Fuel Stabiliser in September 2010, and the Italian mechanism of floating excise on fuel was approved by the Parliament in 2008, but never applied due to budgetary reasons.

${ }^{28}$ It is useful to point out that - following the comparison between eq.(1) and the empirical estimation of pass-through and cost shifting - when stabilization works, there is no extra-budget deriving from VAT on fuel: indeed price stabilization implies that the sum of pre-tax fuel price $P^{f}$ and excise $e x c^{f}$ does not change, but this is exactly the tax-base of the VAT, that therefore remains unchanged.

${ }^{29}$ According to the same estimates, the weight of fuel taxes on public budget ranges from $1.0 \%$ of GDP in Denmark to $2.6 \%$ in Slovenia, and from $2.1 \%$ of total taxation in Denmark to $9.6 \%$ in Bulgaria.
} 
price stabilization policy has a direct and relevant impact on public budgets. Under this perspective, stabilization policies can be seen as redistributive policies targeted to fuel consumers. Table 9 presents some rough simulations of the yearly fuel stabilization costs for the European governments included in our sample under different scenarios, since the uncertainty about the global macroeconomic growth and the geopolitical issues in several oil-exporting countries does not allow to make plausible forecasts on the crude oil price trend. What emerges from the simulation is that even a small price variation $^{30}$ has a non negligible impact on public budgets, and that the amount of per-capita redistribution to fuel consumers is very relevant. As it happens for many other redistributive policies, the final considerations on the opportunity to introduce fuel price stabilization must be done by the policy makers, according to the social support to this kind of policies, that may also change across countries and over time. What this paper shows is that stabilization mechanisms can reach the target, but that the whole burden relies on public budget.

\section{Conclusions}

Fuel price stabilization is often discussed by policy-makers, but it has been effectively implemented in Europe only in few countries and for a very limited period of time. In this paper we test the effectiveness of fuel price stabilization mechanisms using an innovative panel on European countries. As predicted by the theory, we are able to empirically address not only the direct effect of excises and production costs on fuel price, but also the role of VAT and its interactions to excises and production costs. Results show that producers and retailers are able to fully pass on consumers variations of both production costs and excises. For this reason, price stabilization mechanisms such as the 'TIPP flottante' are effective in stabilizing fuel prices following crude oil price volatility. However, the entire burden of stabilization lies on the public budget, and this - together with environmental issues - might be the reason why fuel price stabilization policies are very often proposed by politicians, usually questioned by fiscal authorities and, finally, very hardly implemented.

\footnotetext{
${ }^{30}$ Between late 1990s and late 2000s crude oil price increased by more than $500 \%$. Of course, 'TIPP flottante'-like stabilization mechanisms cannot neutralize oil price increases above $100 \%$, unless governments are ready to subsidize fuel consumption applying a negative excise. Considering also the actual crude oil price level (about $75 \$$ per barrell in November 2014), we limit our simulation to a 50\% increase, that would lead crude oil price to about $110 \$$.
} 


\section{References}

J. Alm, E. Sennoga, and M. Skidmore. Perfect competition, urbanization, and tax incidence in the retail gasoline market. Economic Inquiry, 47(1): 118-134, 2009.

S. A. Borenstein and A. Shepard. Sticky prices, inventories, and market power in wholesale gasoline markets. The RAND Journal of Economics, 33(1):116-139, 2002.

A. C. Cameron, J. B. Gelbach, and D. L. Miller. Robust inference with multiway clustering. Journal of Business \& Economic Statistics, 2:238249, 2011. doi: 10.1198/jbes.2010.07136.

H. Chouinard and J.M. Perloff. Incidence of federal and state gasoline taxes. Economics Letters, 83:55-60, 2004.

H. Chouinard and J.M. Perloff. Gasoline price differences: Taxes, pollution regulations, mergers, market power, and market conditions. The B.E. Journal of Economic Analysis \& Policy, 7(1), 2007.

G. Colangelo and U. Galmarini. Ad valorem taxation on intermediate goods in oligopoly. International Tax and Public Finance, 8(1):53-73, 2001.

S. Delipalla and M. Keen. The comparison between ad valorem and specific taxation under imperfect competition. Journal of Public Economics, 49: 351-367, 1992.

M. Di Giacomo, M. Piacenza, and G. Turati. Are flexible taxation mechanisms effective in stabilizing fuel prices? an evaluation considering wholesale fuel markets. Energy Economics, 34(4):1176-1186, 2012.

J. Doyle and K. Samphantharak. \$2.00 gas! studying the effects of a gas tax moratorium. Journal of Public Economics, 92:869-884, 2008.

Eurostat. Taxation trends in the european union. Eurostat statistical books, European Commission, 2013.

J. S. Hastings and R. J. Gilbert. Market power, vertical integration adn the wholesale price of gasoline. Journal of Industrial Economics, 53(4): 469-492, 2005.

M. Jametti, A. Redonda, and A. Sen. The power to pass on taxes - a test for tax shifting based on observables. CESifo Workin Paper 4265, CESifo, 2013. 
W. Kopczuk, J. Marion, E. Muehlegger, and J. Slemrod. Do the laws of tax incidence hold? point of collection and the pass-through of state diesel taxes. NBER Workin Paper 19410, National Bureau of Economic Research, 2013.

J. Marion and E. Muehlegger. Fuel tax incidence and supply conditions. Journal of Public Economics, 95(9):1202-1212, 2011.

OBR. Assessment of the effect of oil price fluctuations on the public finances. Executive summary, Office for Budget Responsibility, 2010.

The Guardian, Patrick Wintour, political editor. David cameron revives tory plan to curb fuel price rises, Jan 5, 2011.

E. Glen Weyl and Michael Fabinger. Pass-through as an economic tool: Principles of incidence under imperfect competition. Journal of Political Economy, 121(3):528-583, 2013.

A. Zellner. An efficient method of estimating seemingly unrelated regressions and test for aggregation bias. Journal of American Statistical Association, 57(298):348-368, June 1962.

\section{A Tables}

Table 1: Descriptive statistics

\begin{tabular}{lccccc}
\hline \hline \multicolumn{1}{c}{ Variable } & Obs & Mean & Std. Dev. & P10 & P90 \\
\hline Gasoline pre-tax price (Euro per 1000 lt.) & 1998 & 441.54 & 112.81 & 304.67 & 600.19 \\
Diesel pre-tax price (Euro per 1000 lt.) & 1998 & 460.37 & 135.27 & 300.7 & 660.37 \\
Crude oil price (Euro per 1000 lt.) & 1998 & 287.49 & 112.41 & 158.19 & 461.93 \\
Gasoline excise (Euro per 1000 lt.) & 1998 & 506.97 & 98.14 & 374.08 & 628.12 \\
Diesel excise (Euro per 1000 lt.) & 1998 & 344.29 & 58.28 & 268.4 & 424.93 \\
Gasoline VAT (in \%) & 1998 & 19.13 & 2.47 & 16 & 22 \\
Diesel VAT (in \%) & 1998 & 19.24 & 2.21 & 16 & 22 \\
Number of retailers (per 100,000 vehicles) & 1056 & 50.36 & 19.41 & 32.18 & 69.39 \\
Number of vehicles (per 1,000 people) & 1368 & 596.23 & 65.4 & 518.03 & 685.83 \\
Share of population over 65 (in \%) & 1986 & 16.27 & 2.3 & 13.6 & 19.25 \\
Per capita GDP /1000 (Euro) & 1977 & 7.23 & 3.03 & 3.9 & 9.92 \\
Market share of the leader & 1830 & .28 & .08 & .19 & .38 \\
Tobacco excise (\% of final price) & 1998 & 59.62 & 2.72 & 57 & 64 \\
\hline
\end{tabular}

Note: Prices, excises and GDP are in 2005 Euros. 
Table 2: Baseline regressions.

\begin{tabular}{|c|c|c|c|c|c|c|c|c|}
\hline & \multicolumn{4}{|c|}{ Gasoline } & \multicolumn{4}{|c|}{ Diesel } \\
\hline & (1) & $(2)$ & (3) & (4) & $(5)$ & (6) & (7) & (8) \\
\hline & $\mathrm{b} / \mathrm{se}$ & $\mathrm{b} / \mathrm{se}$ & $\mathrm{b} / \mathrm{se}$ & $\mathrm{b} / \mathrm{se}$ & $\mathrm{b} / \mathrm{se}$ & $\mathrm{b} / \mathrm{se}$ & $\mathrm{b} / \mathrm{se}$ & $\mathrm{b} / \mathrm{se}$ \\
\hline \multirow[t]{2}{*}{ Oil price } & $0.930^{* * *}$ & $0.898^{* * *}$ & $1.077^{* * *}$ & $0.764^{* * *}$ & $0.914^{* * *}$ & $0.981^{* * *}$ & $1.047^{* * *}$ & $0.584^{* * *}$ \\
\hline & 0.089 & 0.176 & 0.337 & 0.227 & 0.057 & 0.099 & 0.232 & 0.171 \\
\hline \multirow[t]{2}{*}{ Excise } & $-0.153^{*}$ & -0.806 & -1.196 & $0.763^{*}$ & -0.112 & $1.206^{* * *}$ & 1.071 & $0.604^{*}$ \\
\hline & 0.086 & 0.534 & 0.903 & 0.401 & 0.076 & 0.456 & 0.651 & 0.359 \\
\hline \multirow{2}{*}{ VAT } & 1.988 & -15.642 & -26.181 & $26.063^{*}$ & $11.705^{* * *}$ & $35.887 * * *$ & $24.207^{* *}$ & 12.804 \\
\hline & 2.452 & 12.781 & 22.261 & 15.703 & 3.153 & 10.270 & 11.727 & 10.098 \\
\hline \multirow[t]{2}{*}{ Oil price $\times$ VAT } & & 0.001 & -0.009 & 0.008 & & -0.003 & -0.007 & $0.021^{* *}$ \\
\hline & & 0.009 & 0.016 & 0.011 & & 0.006 & 0.013 & 0.009 \\
\hline \multirow[t]{2}{*}{ Excise $\times$ VAT } & & 0.034 & 0.051 & $-0.042^{*}$ & & $-0.068^{* * *}$ & $-0.060^{*}$ & -0.034 \\
\hline & & 0.025 & 0.043 & 0.022 & & 0.025 & 0.034 & 0.021 \\
\hline Country time trends & No & No & Yes & No & No & No & Yes & No \\
\hline Controls & No & No & No & Yes & No & No & No & Yes \\
\hline Monthly f.e. & Yes & Yes & Yes & Yes & Yes & Yes & Yes & Yes \\
\hline Yearly f.e. & Yes & Yes & Yes & Yes & Yes & Yes & Yes & Yes \\
\hline Country f.e. & Yes & Yes & Yes & Yes & Yes & Yes & Yes & Yes \\
\hline Obs. & 1998 & 1998 & 1998 & 1044 & 1998 & 1998 & 1998 & 1044 \\
\hline Adj. $R^{2}$ & 0.94 & 0.94 & 0.95 & 0.96 & 0.96 & 0.97 & 0.97 & 0.98 \\
\hline Years & 14 & 14 & 14 & 14 & 14 & 14 & 14 & 14 \\
\hline Months & 12 & 12 & 12 & 12 & 12 & 12 & 12 & 12 \\
\hline Countries & 12 & 12 & 12 & 12 & 12 & 12 & 12 & 12 \\
\hline
\end{tabular}

Note: Coefficients and standard errors are shown. Standard errors are clustered at year, country, and month level. ${ }^{*} p<0.1,{ }^{* *} p<0.05,{ }^{* * *} p<0.01$. Columns $(1,5)$ : baseline model; Columns $(2,6)$ : including interactions between VAT and excise and crude oil price; Columns (3,7): including also country-specific time trends up to order 3; Columns $(4,8)$ : country-specific time trends replaced by the following controls: number of retailers / 1,000 vehicles, number of vehicles / 1,000 people, share of population over 65, per-capita GDP. 
Table 3: Robustness checks for market shares and elasticity.

\begin{tabular}{|c|c|c|c|c|c|c|}
\hline & \multicolumn{3}{|c|}{ Gasoline } & \multicolumn{3}{|c|}{ Diesel } \\
\hline & \multicolumn{2}{|c|}{ Market shares } & \multirow{3}{*}{$\begin{array}{c}\text { Elasticity } \\
(3) \\
\text { b/se }\end{array}$} & \multicolumn{2}{|c|}{ Market shares } & \multirow{3}{*}{$\begin{array}{c}\text { Elasticity } \\
(6) \\
\text { b/se }\end{array}$} \\
\hline & (1) & $(2)$ & & $(4)$ & $(5)$ & \\
\hline & $\mathrm{b} / \mathrm{se}$ & $\mathrm{b} / \mathrm{se}$ & & $\mathrm{b} / \mathrm{se}$ & $\mathrm{b} / \mathrm{se}$ & \\
\hline \multirow[t]{2}{*}{ Oil price } & -0.093 & $1.818^{*}$ & $0.502^{*}$ & 0.223 & 0.645 & $0.623^{*}$ \\
\hline & 1.122 & 0.978 & 0.270 & 0.949 & 1.059 & 0.369 \\
\hline \multirow[t]{2}{*}{ Excise } & -2.213 & -0.177 & -2.338 & 0.466 & 1.289 & $3.257^{* *}$ \\
\hline & 1.882 & 0.938 & 2.323 & 0.952 & 1.127 & 1.643 \\
\hline \multirow[t]{2}{*}{ VAT } & $-110.085^{*}$ & $-64.520 * * *$ & -4.507 & 16.248 & $34.375^{* * *}$ & $6.749^{* *}$ \\
\hline & 63.665 & 13.820 & 4.807 & 23.656 & 12.637 & 3.108 \\
\hline \multirow[t]{2}{*}{ Oil price $\times \mathrm{VAT}$} & 0.049 & -0.043 & 0.023 & 0.032 & 0.021 & -0.043 \\
\hline & 0.056 & 0.050 & 0.093 & 0.049 & 0.055 & 0.126 \\
\hline \multirow[t]{2}{*}{ Excise $\times$ VAT } & 0.103 & 0.033 & 0.695 & -0.038 & -0.066 & $-1.117^{* *}$ \\
\hline & 0.089 & 0.030 & 0.775 & 0.048 & 0.044 & 0.553 \\
\hline Country time trends & No & Yes & Yes & No & Yes & Yes \\
\hline Market shares inter. & No & Yes & No & No & Yes & No \\
\hline Country time tr. inter. & Yes & No & No & Yes & No & No \\
\hline Monthly f.e. & Yes & Yes & Yes & Yes & Yes & Yes \\
\hline Yearly f.e. & Yes & Yes & Yes & Yes & Yes & Yes \\
\hline Country f.e. & Yes & Yes & Yes & Yes & Yes & Yes \\
\hline Obs. & 1998 & 1830 & 1998 & 1998 & 1830 & 1998 \\
\hline Adj. $R^{2}$ & 0.96 & 0.95 & 0.95 & 0.98 & 0.97 & 0.97 \\
\hline Years & 14 & 14 & 14 & 14 & 14 & 14 \\
\hline Months & 12 & 12 & 12 & 12 & 12 & 12 \\
\hline Countries & 12 & 12 & 12 & 12 & 12 & 12 \\
\hline
\end{tabular}

Note: Coefficients and standard errors are shown. Standard errors are clustered at year, country, and month level. ${ }^{*} p<0.1,{ }^{* *} p<0.05,{ }^{* * *} p<0.01$. Columns $(1,4)$ : interacted terms included: Oil Price X country-specific time trends, Excise X country-specific time trends, Oil Price X VAT X country-specific time trends, Excise X VAT X country-specific time trends (all time trends in degree 1, 2, 3); Columns $(2,5)$ : interacted terms included: Oil Price X Market share, Excise X Market share, Oil Price X VAT X Market share, Excise X VAT X Market share; Columns (3,6): all the variables in logarithms. 
Table 4: Robustness checks for endogeneity.

\begin{tabular}{l|cc|cc}
\hline \hline \multirow{2}{*}{ Sample } & IV & \multicolumn{2}{c}{ Diesel } \\
& $(1)$ & $(2)$ & $(3)$ & $(4)$ \\
& $\mathrm{b} / \mathrm{se}$ & $\mathrm{b} / \mathrm{se}$ & $\mathrm{b} / \mathrm{se}$ & $\mathrm{b} / \mathrm{se}$ \\
\hline Oil price & $0.980^{* * *}$ & $1.018^{* * *}$ & $1.143^{* * *}$ & $1.054^{* * *}$ \\
Excise & 0.228 & 0.248 & 0.197 & 0.206 \\
& $0.613^{* * *}$ & 0.208 & 0.783 & 0.728 \\
VAT & 0.217 & 0.618 & 0.704 & 0.717 \\
& $9.882^{*}$ & -15.883 & 22.997 & 17.112 \\
Oil price $\times$ VAT & 5.880 & 30.607 & 16.266 & 11.376 \\
& -0.004 & -0.007 & -0.012 & -0.008 \\
Excise $\times$ VAT & 0.012 & 0.012 & 0.011 & 0.011 \\
Country time trends & $-0.027^{* * *}$ & 0.009 & -0.047 & -0.040 \\
Monthly f.e. & 0.010 & 0.044 & 0.037 & 0.030 \\
Yearly f.e. & Yes & Yes & Yes & Yes \\
Country f.e. & Yes & Yes & Yes & Yes \\
\hline Obs. & Yes & Yes & Yes & Yes \\
Adj. R ${ }^{2}$ & Yes & Yes & Yes & Yes \\
Years & 1662 & 1998 & 1662 & 1998 \\
Months & 0.95 & 0.94 & 0.97 & 0.97 \\
Countries & 14 & 14 & 14 & 14 \\
\hline
\end{tabular}

Note: Coefficients and standard errors are shown. Standard errors are clustered at year, country, and month level. ${ }^{*} p<0.1,{ }^{* *} p<0.05,{ }^{* * *} p<0.01$. Columns $(1,3)$ : France and Portugal excluded from the sample; Column $(2,4)$ : excise on tobacco as an instrument for fuel excise. 
Table 5: IV regressions: first-stage.

\begin{tabular}{l|c|c}
\hline \hline & Gasoline & Diesel \\
& $(1)$ & $(2)$ \\
& $\mathrm{b} / \mathrm{se}$ & $\mathrm{b} / \mathrm{se}$ \\
\hline Excise on tobacco & $3.905^{* * *}$ & $2.262^{* * *}$ \\
& 0.431 & 0.286 \\
Oil price & -0.039 & -0.007 \\
& 0.064 & 0.047 \\
VAT & $16.857^{* * *}$ & $7.207^{* * *}$ \\
& 1.505 & 1.192 \\
Oil price $\times$ VAT & 0.003 & 0.001 \\
& 0.003 & 0.002 \\
Country time trends & Yes & Yes \\
Monthly f.e. & Yes & Yes \\
Yearly f.e. & Yes & Yes \\
Country f.e. & Yes & Yes \\
\hline Obs. & 1998 & 1998 \\
Adj. R ${ }^{2}$ & 0.96 & 0.94 \\
F test & $596.67^{* * *}$ & $471.50^{* * *}$ \\
\hline
\end{tabular}

Note: Coefficients and standard errors are shown. Standard errors are clustered at year, country, and month level. ${ }^{*} p<0.1,{ }^{* *} p<0.05,{ }^{* * *} p<0.01$. Dependent variables are the excises on gasoline $(1)$ and diesel (2). 
Table 6: Estimated effects of baseline models.

\begin{tabular}{l|cccc|cccc}
\hline \hline & \multicolumn{5}{|c|}{ Gasoline } & \multicolumn{4}{c}{ Diesel } \\
& $(1)$ & $(2)$ & $(3)$ & $(4)$ & $(5)$ & $(6)$ & $(7)$ & $(8)$ \\
& $\mathrm{b} / \mathrm{se}$ & $\mathrm{b} / \mathrm{se}$ & $\mathrm{b} / \mathrm{se}$ & $\mathrm{b} / \mathrm{se}$ & $\mathrm{b} / \mathrm{se}$ & $\mathrm{b} / \mathrm{se}$ & $\mathrm{b} / \mathrm{se}$ & $\mathrm{b} / \mathrm{se}$ \\
\hline$\frac{\partial P^{d}}{\partial o i l P}$ & 0.930 & 0.923 & 0.900 & 0.925 & 0.914 & 0.919 & 0.907 & 0.991 \\
& 0.089 & 0.091 & 0.100 & 0.089 & 0.057 & 0.067 & 0.061 & 0.042 \\
$\frac{\partial P^{d}}{\partial e x c^{d}}+1$ & 0.847 & 0.846 & 0.778 & 0.954 & 0.888 & 0.904 & 0.925 & 0.945 \\
& 0.086 & 0.078 & 0.151 & 0.045 & 0.076 & 0.061 & 0.099 & 0.075 \\
$\frac{\partial P^{f}}{\partial o i l P}-\frac{\partial P^{f}}{\partial e x c^{f}}-1$ & 0.083 & 0.077 & 0.123 & -0.029 & 0.026 & 0.015 & -0.018 & 0.046 \\
& 0.146 & 0.138 & 0.193 & 0.107 & 0.077 & 0.112 & 0.111 & 0.077 \\
$C P^{d}$ ex-ante & 1.130 & 1.130 & 1.130 & 1.130 & 0.959 & 0.959 & 0.959 & 0.959 \\
&. &. &. &. &. &. &. &. \\
$C P^{d}$ ex-post & 1.140 & 1.139 & 1.145 & 1.126 & 0.963 & 0.961 & 0.957 & 0.965 \\
$\Delta C P^{d}$ & 0.017 & 0.016 & 0.023 & 0.013 & 0.009 & 0.013 & 0.013 & 0.009 \\
& 0.010 & 0.009 & 0.015 & -0.003 & 0.003 & 0.002 & -0.002 & 0.005 \\
$\mathrm{p}-\mathrm{values}$ for $H_{0}:$ & 0.017 & 0.016 & 0.023 & 0.013 & 0.009 & 0.013 & 0.013 & 0.009 \\
$\frac{\partial P^{d}}{\partial o i l P}=1$ & & & & & & & & \\
$\frac{\partial P^{d}}{\partial e x c^{d}}+1=1$ & 0.434 & 0.397 & 0.319 & 0.398 & 0.129 & 0.223 & 0.125 & 0.824 \\
$\frac{\partial P^{f}}{\partial o i l P}-\frac{\partial P^{f}}{\partial e x c^{f}}-1=0$ & 0.077 & 0.048 & 0.142 & 0.311 & 0.140 & 0.113 & 0.448 & 0.465 \\
\hline
\end{tabular}

Note: All standard errors are based on estimations in table 2 and computed using the delta method. Effects on prices are simulated assuming a $\Delta o i l P=-\Delta e x c=.10$ variation of both crude oil price and excise. Underlying models: Columns $(1,5)$ : baseline model; Columns $(2,6)$ : including interactions between VAT and excise and crude oil price; Columns (3,7): including also country-specific time trends up to order 3; Columns (4,8): country-specific time trends replaced by the following controls: number of retailers / 1,000 vehicles, number of vehicles / 1,000 people, share of population over 65, per-capita GDP. 
Table 7: Estimated effects on robustness checks for market shares and elasticity.

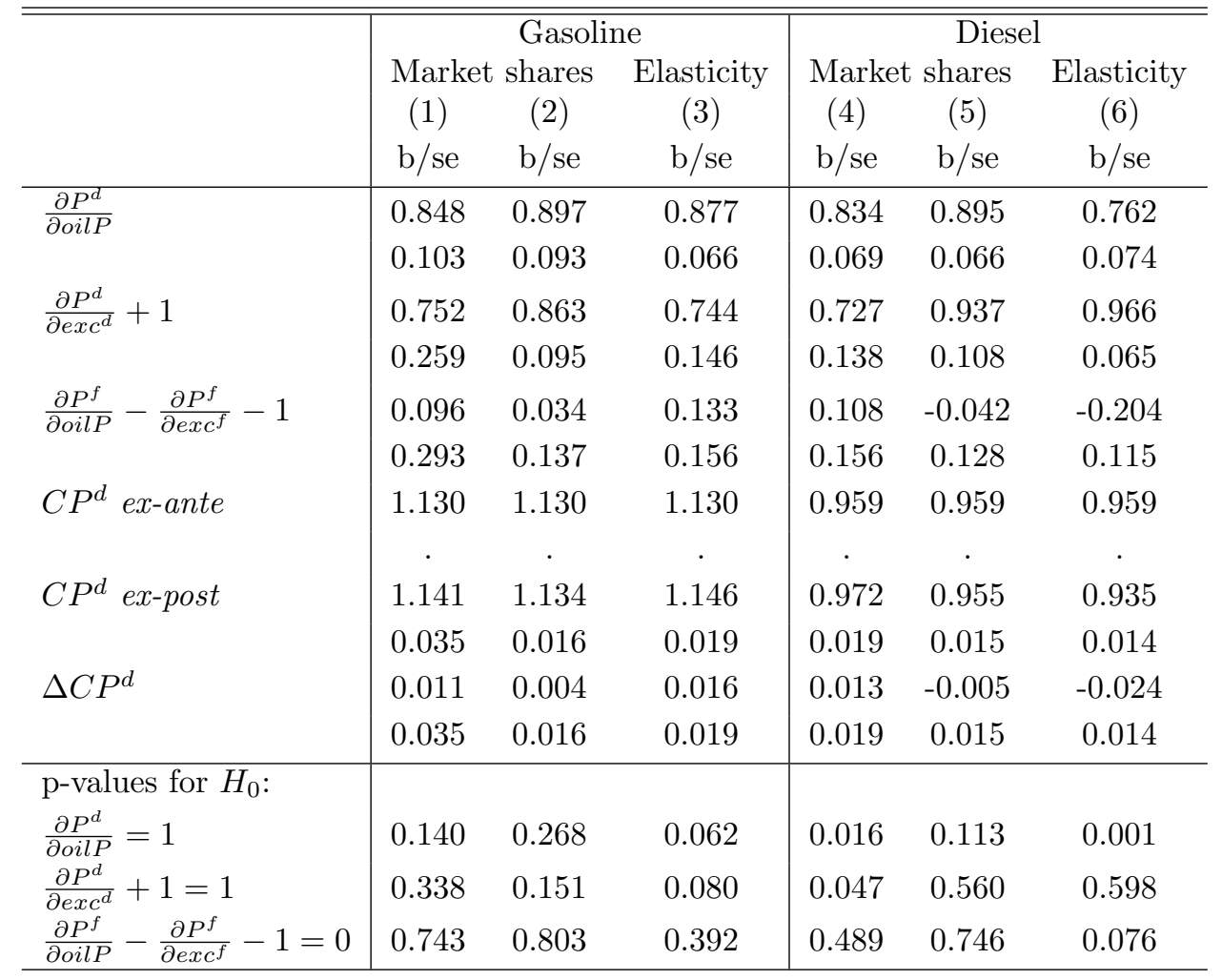

Note: All standard errors are based on estimations in table 3 and computed using the delta method. Effects on prices are simulated assuming a $\Delta$ oilP $=-\Delta e x c=.10$ variation of both crude oil price and excise. Underlying models: Columns $(1,4)$ : interacted terms included: Oil Price X country-specific time trends, Excise X country-specific time trends, Oil Price X VAT X country-specific time trends, Excise X VAT X country-specific time trends (all time trends in degree 1, 2, 3); Columns (2,5): interacted terms included: Oil Price X Market share, Excise X Market share, Oil Price X VAT X Market share, Excise X VAT X Market share; Columns (3,6): all the variables in logarithms. 
Table 8: Estimated effects on robustness checks for endogeneity.

\begin{tabular}{|c|c|c|c|c|}
\hline & \multicolumn{2}{|c|}{ "Gasoline } & \multicolumn{2}{|c|}{ 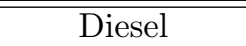 } \\
\hline & $\begin{array}{c}\text { Sample } \\
(1)\end{array}$ & $\begin{array}{l}\text { IV } \\
(2)\end{array}$ & $\begin{array}{c}\text { Sample } \\
(3)\end{array}$ & $\begin{array}{l}\text { IV } \\
(4)\end{array}$ \\
\hline & $\mathrm{b} / \mathrm{se}$ & $\mathrm{b} / \mathrm{se}$ & $\mathrm{b} / \mathrm{se}$ & $\mathrm{b} / \mathrm{se}$ \\
\hline \multirow[t]{2}{*}{$\frac{\partial P^{d}}{\partial o i l P}$} & 0.895 & 0.888 & 0.915 & 0.906 \\
\hline & 0.095 & 0.096 & 0.066 & 0.059 \\
\hline \multirow{2}{*}{$\frac{\partial P^{d}}{\partial e x c^{d}}+1$} & 1.109 & 1.387 & 0.883 & 0.953 \\
\hline & 0.087 & 0.502 & 0.100 & 0.306 \\
\hline \multirow{2}{*}{$\frac{\partial P^{f}}{\partial o i l P}-\frac{\partial P^{f}}{\partial e x c^{f}}-1$} & -0.213 & -0.499 & 0.031 & -0.047 \\
\hline & 0.142 & 0.499 & 0.105 & 0.293 \\
\hline \multirow[t]{2}{*}{$C P^{d}$ ex-ante } & 1.121 & 1.130 & 0.959 & 0.959 \\
\hline & . & . & . & . \\
\hline \multirow[t]{2}{*}{$C P^{d}$ ex-post } & 1.096 & 1.071 & 0.962 & 0.954 \\
\hline & 0.017 & 0.059 & 0.012 & 0.035 \\
\hline \multirow[t]{2}{*}{$\Delta C P^{d}$} & -0.025 & -0.059 & 0.004 & -0.006 \\
\hline & 0.017 & 0.059 & 0.012 & 0.035 \\
\hline \multicolumn{5}{|l|}{ p-values for $H_{0}$ : } \\
\hline$\frac{\partial P^{d}}{\partial o i l P}=1$ & 0.271 & 0.244 & 0.196 & 0.111 \\
\hline$\frac{\partial P^{d}}{\partial e x c^{d}}+1=1$ & 0.214 & 0.441 & 0.244 & 0.877 \\
\hline$\frac{\partial P^{f}}{\partial o i l P}-\frac{\partial P^{f}}{\partial e x c^{f}}-1=0$ & 0.134 & 0.318 & 0.766 & 0.873 \\
\hline
\end{tabular}

Note: All standard errors are based on estimations in table 4 and computed using the delta method. Effects on prices are simulated assuming a $\Delta o i l P=-\Delta e x c=.10$ variation of both crude oil price and excise. Underlying models: Columns (1,3): France and Portugal excluded from the sample; Columns $(2,4)$ : excise on tobacco as an instrument for fuel excise. 
Table 9: Simulated stabilization costs following a Brent crude oil price rise.

\begin{tabular}{cccccccc}
\hline \hline Country & $\begin{array}{c}\text { Fuel tax/GDP } \\
(\%)\end{array}$ & \multicolumn{3}{c}{$\begin{array}{c}\text { Public budget } \\
\text { (millions Euro) }\end{array}$} & \multicolumn{3}{c}{$\begin{array}{c}\text { Individuals } \\
\text { (Euro per capita) }\end{array}$} \\
& & \multicolumn{3}{c}{ Oil price increase: } & \multicolumn{2}{c}{ Oil price increase: } \\
& & $10 \%$ & $25 \%$ & $50 \%$ & $10 \%$ & $25 \%$ & $50 \%$ \\
\hline AT & 1.3 & 412 & 1030 & 2060 & 50 & 125 & 251 \\
BE & 1.1 & 408 & 1019 & 2039 & 39 & 98 & 196 \\
DK & 1.0 & 186 & 465 & 930 & 34 & 84 & 169 \\
FI & 1.3 & 225 & 563 & 1127 & 43 & 107 & 214 \\
FR & 1.2 & 2433 & 6082 & 12163 & 38 & 94 & 188 \\
DE & 1.4 & 3896 & 9740 & 19480 & 48 & 119 & 239 \\
GR & 1.6 & 434 & 1085 & 2169 & 40 & 101 & 202 \\
IE & 1.3 & 210 & 524 & 1049 & 45 & 113 & 227 \\
IT & 1.6 & 2759 & 6896 & 13793 & 45 & 114 & 227 \\
LU & 2.2 & 83 & 207 & 414 & 166 & 416 & 831 \\
NL & 1.3 & 833 & 2083 & 4166 & 50 & 124 & 248 \\
ES & 1.1 & 1398 & 3496 & 6991 & 30 & 75 & 150 \\
\hline
\end{tabular}




\section{DEPARTMENT OF ECONOMICS AND STATISTICS \\ UNIVERSITY OF TORINO}

Corso Unione Sovietica 218 bis - 10134 Torino (ITALY)

Web page: http://esomas.econ.unito.it/ 